\title{
Seleção de diretores de escolas públicas: argumentos sobre o mérito do candidato
}

\author{
Selection of public school principals: \\ arguments about the merit of the candidate \\ Selección de directores de escuelas públicas:
}

DANiEla PATti do Amaral $\mathbb{1}$

Universidade Federal do Rio de Janeiro, Rio de Janeiro, RJ, Brasil. $\diamond$

\begin{abstract}
RESUMO
O Plano Nacional de Educação (PNE) (BRASIL, 2014) determinou aos entes federados a aprovação de legislação disciplinando a gestão democrática da educação pública associada a critérios técnicos de mérito e desempenho e à consulta à comunidade escolar. Este trabalho aborda os requisitos atribuídos ao mérito presentes na legislação de três municípios do estado do Rio de Janeiro: Rio de Janeiro, Duque de Caxias e Valença. Há consenso que os candidatos à direção da escola deverão ser servidores efetivos, ter experiência docente e não ter pendências administrativas ou judiciais. No entanto, não há consenso sobre a formação do candidato. Avaliamos que as formas como cada ente federado ressignifica e hibridiza a categoria mérito se apresenta através de distintas maneiras, tendo em vista a autonomia dos entes federados, o momento político vivido em cada município/estado, as infidelidades normativas e a forma elástica como se apropriam da norma que orienta a ação, no caso, o PNE.
\end{abstract}

Palavras-chave: Plano Nacional de Educação. Gestão escolar. Gestão democrática. Mérito.

\begin{abstract}
According to PNE (BRASIL, 2014), states and municipalities should approve legislation regulating the democratic management of public education associated with technical criteria of merit. This paper deals with the requirements attributed to merit present in the legislation of three municipalities of the state of Rio de Janeiro - Rio de Janeiro, Duque de Caxias, and Valença. There is a consensus that candidates for the direction of the school should be effective servants, have teaching experience without administrative or judicial pending. However, there is no consensus on the candidate's training. We evaluate that the way in which each federated entity resigns and hybridizes to the merit category presents itself in different ways in view of the autonomy of the federated entities, the political moment lived in each municipality / state, the normative infidelities and the elastic form as they appropriate norm that guides the action, in this case, the PNE.
\end{abstract}

Keywords: National Education Plan. School management. Democratic management. Merit.

\section{RESUMEN}

El Plan Nacional de Educación (BRASIL, 2014) determinó a los entes federados la aprobación de legislación disciplinando la gestión democrática de la educación pública asociada a criterios técnicos de mérito y desempeño ya la consulta a la comunidad escolar. Este trabajo aborda los requisitos atribuidos al mérito presentes en la legislación de tres municipios del estado de Río de Janeiro - Río de Janeiro, Duque de Caxias y Valença. Hay consenso que los candidatos a la dirección de la escuela deberán ser servidores efectivos, tener experiencia docente y no tener pendientes administrativas o judiciales. Sin embargo, no hay consenso sobre la formación del candidato. Se evaluó que las formas como cada ente federado resignifica e hibridiza la categoría mérito se presenta a través de distintas maneras teniendo en vista la autonomía de los entes federados, el momento político vivido en cada municipio / estado, las infidelidades normativas y la forma elástica como se apropian de la norma que orienta la acción, en el caso, el PNE.

Palabras clave: Plan Nacional de Educación. Gestión escolar. Gestión democrática. Mérito. 


\section{INTRODUÇÃo}

A gestão democrática das escolas públicas é um princípio presente em diferentes documentos legais brasileiros em âmbito nacional (BRASIL, 1988; BRASIL, 1996; BRASIL, 2014). Arelalo, Jacomini e Carneiro (2016) argumentam que a redação dada pela Lei de Diretrizes e Bases (LDB) de 1996 ao tema da gestão democrática frustrou aqueles que esperavam detalhamento acerca da efetivação de procedimentos concretos nos sistemas de ensino. Conforme os autores, ao estabelecer apenas os princípios gerais, a LDB

\begin{abstract}
deixou para cada sistema de ensino definir, entre outros aspectos: a forma do provimento do diretor de escola, quais conselhos instituir, a proporção de participação de cada segmento e o caráter deliberativo ou consultivo desses blocos. Portanto, vários aspectos de caráter mais específico para a forma de efetivação da gestão democrática foram negligenciados, mediante a prevalência da ideia e do argumento de se produzir uma lei "enxuta" (ARELALO; JACOMINI; CARNEIRO, 2016, p. 1146-1147).
\end{abstract}

O Plano Nacional de Educação (PNE) ratificou o princípio da gestão democrática no artigo 9 으o ao determinar que os estados, o Distrito Federal e os municípios deverão aprovar leis específicas para os seus sistemas de ensino, disciplinando a gestão democrática da educação pública (BRASIL, [2014]). A meta 19 do documento (Lei no $13.005,25$ de junho de 2014) determina

assegurar condições, no prazo de 2 (dois) anos, para a efetivação da gestão democrática da educação, associada a critérios técnicos de mérito e desempenho e à consulta pública à comunidade escolar, no âmbito das escolas públicas, prevendo recursos e apoio técnico da União para tanto (BRASIL, [2014]).

Na estratégia 19.1, o PNE estabeleceu que será priorizado o repasse de transferências voluntárias da União na área da educação para os entes federados que tenham aprovado legislação específica que regulamente a gestão democrática, respeitando-se a legislação nacional, e que considere, conjuntamente, para a nomeação dos diretores e diretoras de escola, critérios técnicos de mérito e desempenho, bem como a participação da comunidade escolar.

Tendo em vista as três categorias que deverão ser observadas - o mérito e o desempenho do candidato associados à consulta à comunidade, o presente trabalho aborda quais requisitos atribuídos à categoria mérito foram aprovados na legislação dos municípios do estado do Rio de Janeiro.
Partimos do pressuposto de que mérito é uma categoria complexa de aprofundamento, em especial em uma sociedade desigual como a brasileira. Valle (2013, p. 688) argumenta que o mérito só tem sentido em uma sociedade que valoriza algumas capacidades mais que outras, não sendo transparente, nem neutro, como vislumbravam os idealizadores do projeto republicano. Nessa perspectiva, aquilo que cada rede pública de educação definir como mérito para alguém se candidatar à direção de uma escola pública pode assumir múltiplos significados, dificultando consensos sobre o que deve ser levado em conta na avaliação do perfil do candidato e quais procedimentos serão utilizados para definir o mérito de cada um. Logo, definir quais as habilidades necessárias e o que é mais importante face ao fato de o candidato merecer ocupar a função de diretor de uma escola pública não é tarefa simples. Em especial, quando se pensa em uma gestão escolar em uma perspectiva democrática.

Tendo em vista a aprovação do PNE, em junho de 2014, os entes federados tiveram o prazo de dois anos, a partir da publicação do Plano Nacional, para aprovarem seus respectivos planos e, posteriormente, aprovarem legislação específica que discipline a gestão democrática da educação pública para os seus sistemas de ensino. Essa legislação deverá considerar conjuntamente, para a nomeação dos diretores de escola, critérios técnicos de mérito e desempenho, bem como a participação da comunidade escolar. Destacamos a amplitude do termo legislação específica - a gestão democrática tanto poderá ser regulamenta por uma lei como através de um decreto, portaria, resolução ou demais mecanismos legais, marcando, dessa maneira, formas distintas de debate e participação da comunidade em cada ente federado.

Segundo Lima (2011, p. 170), o estudo das diferentes legislações não esgota a compreensão das realidades, mas são importantes fontes de pesquisa. $\mathrm{O}$ autor destaca a importância da busca por fontes diversas como textos de recepção, de interpretação e de recriação das mudanças decididas pelos atores políticos e administrativos centrais. Conforme o autor,

o estudo das mudanças operadas historicamente no sistema educativo e nas escolas envolve sempre, com maior ou menor incidência, o recurso a uma vasta gama de textos, de variada origem, de distintos tipos e categorias, de circulação e alcance diversos: textos políticos e programáticos, propostas e documentos preparatórios, textos jurídicos e normativos (LIMA, 2011, p. 166).

Lima destaca, no contexto das reformas educacionais ocorridas em Portugal, que os planos, as reformas, além das leis de bases e outros ordenamentos e estatutos são categorias jurídicas ou textuais que há mais de 
duzentos anos vêm marcando a construção social e o desenvolvimento do sistema escolar, assim como a organização e administração das escolas portuguesas. Nesse processo, afirma o autor, se encontram as próprias instâncias centrais de produção e reprodução normativa e de controle da educação no País, desde a "Directoria-Geral dos Estudos" criada em 1759 por Marques de Pombal até o atual Ministério da Educação. Como afirmado por Lima (2014, p 1068),

considerando a segunda metade do século XX, em países que, como Portugal e o Brasil, experimentaram durante longos períodos a vigência de regimes autoritários, talvez seja difícil encontrar um ideal político-educativo mais pleno de significado democrático e com maior potência transformadora do que aquele que, tendo sido assumido como utopia, reivindicação e palavra-de-ordem, foi expresso através da categoria gestão democrática das escolas.

Em Portugal, segundo Lima (2014) a gestão democrática das escolas representava uma categoria do discurso político da oposição democrática e dos movimentos estudantis antes da Revolução de 25 de abril de $1974{ }^{1}$. No caso brasileiro, segundo Lima (2012), antes mesmo da promulgação da Constituição Federal de 1988, alguns estados e municípios já adotavam a eleição de diretores em suas redes de ensino como corolário da democratização que pretendiam afirmar.

Concordamos com Souza (2009, p. 125) quando ele afirma que a gestão democrática deve ser entendida como um processo político no qual "as pessoas que atuam na/sobre a escola identificam problemas, discutem, deliberam e planejam, encaminham, acompanham, controlam e avaliam o conjunto das ações voltadas ao desenvolvimento da própria escola na busca da solução daqueles problemas". Um processo que, segundo o autor, tem como base a participação efetiva de todos os segmentos da comunidade escolar, o respeito às normas coletivamente construídas para os processos de tomada de decisões e, ainda, a garantia de amplo acesso às informações aos sujeitos da escola. Conforme destacado pelo autor "a gestão escolar, pelas determinações legais, deve ser pautada pelo princípio e pelo método democrático. Todavia, há pouca clareza sobre o que significa a tradução de um em outro, na ação concreta nas escolas públicas país afora" (SOUZA, 2009, p. 124). Nesse contexto e na perspectiva de compreender a relação

\footnotetext{
${ }^{1}$ Lima (2014) afirma que a gestão democrática já era uma reivindicação expressa durante as crises universitárias da década de 1960 com repercussões em toda a educação. Devido à transição para democracia em Portugal registrou-se, a partir dos primeiros dias após a Revolução dos Cravos ocorrida em 1974, uma ruptura com formas autocráticas de governo escolar que haviam se estabelecido ao longo de quase meio século.
}

do mérito do candidato à direção das escolas e a uma gestão democrática, o presente artigo apresenta de que forma a categoria mérito, prevista na meta 19 do PNE para a seleção de diretores tem sido compreendida por alguns municípios do estado do Rio de Janeiro nos seus documentos legais que disciplinam a gestão democrática e a seleção de diretores das escolas públicas.

Acerca do provimento da direção de escolas, dados do Instituto Nacional de Estudos e Pesquisas Educacionais Anisio Teixeira (INEP, 2016) apontam que 45,5\% dos diretores que atuam na gestão das escolas públicas no País foram indicados e apenas $21 \%$ foram eleitos. Os que chegaram via concurso público somam $7,6 \%$, sendo que $3,3 \%$ foram submetidos a algum processo seletivo; $5,2 \%$ por processo seletivo somado à indicação; $5,2 \%$ através de outras formas e $12,2 \%$ através de processo seletivo e eleição. Observa-se um cenário diverso na seleção de diretores e, nesse aspecto, indagamos como cada ente federado irá definir o mérito do candidato. Quais critérios definir? Destacamos, com base em Luck (2011), que não há na literatura estudos demonstrativos da efetividade das políticas de seleção de diretores, independentemente da modalidade de seleção adotada. Logo, esse não é um território de consensos fáceis.

As agendas que influenciaram a elaboração do PNE (BRASIL, 2014) resultaram no texto final da Lei que serve de plano de orientação para os estados e municípios visto a necessidade de alinhamento dos planos educacionais dos entes federados às metas e estratégias estabelecidas no PNE. Entretanto, os atores envolvidos no debate e elaboração dos planos no âmbito dos estados e municípios ressignificam e hibridizam, produzindo uma apropriação mais ou menos elástica dos textos da lei nacional na consolidação das suas legislações próprias. No contexto da aprovação dos mecanismos que irão assegurar a gestão democrática nas escolas públicas, os poderes executivo e legislativo têm papel fundamental na sanção da legislação que irá materializar questões que abarcam a gestão democrática tais como o processo de seleção de diretores de escolas, composição dos conselhos escolares e grêmios estudantis, associação de pais e responsáveis, dentre outros aspectos.

Nesse contexto, vale destacar as tensões presentes na elaboração da legislação que regulamenta a gestão democrática e o processo de seleção dos diretores das escolas públicas a partir de uma escala de maior ou menor participação da população na elaboração do documento dependendo da sua natureza. A regulamentação da gestão democrática tem ocorrido através de diferentes mecanismos: via decreto, resolução, portaria e projeto de lei. Ponderamos que essas estratégias sinalizam a escala de participação dos destinatários das políticas tendo em vista que tanto um decreto como uma 
resolução ou portaria são documentos promulgados pelo executivo e que podem ser revogados a qualquer momento, dando fragilidade ao processo já que não foi objeto de negociação, debate e audiências públicas no legislativo. Dessa maneira, ressaltamos a fragilidade legal de uma resolução, portaria ou decreto sem o valor e o capital simbólico de uma lei aprovada após debate com a sociedade e diferentes processos de negociação. Mendonça (2001, p. 98) já sinalizava quase 20 anos atrás que "a posição hierárquica do instrumento legal utilizado na institucionalização de diretrizes políticas na área educacional parece ser um fator indicador da menor ou maior perenidade dessas diretrizes". Compreendemos que, mesmo após regulamentação nesses municípios, a gestão democrática e o processo de seleção de diretores de escola pública ainda podem se encontrar em terreno de frágil democracia e pouca ou nenhuma participação praticada dos destinatários das políticas.

Os planos de educação - nacional, estaduais e municipais - são textos políticos construídos a partir de uma agenda e em diferentes contextos que influenciaram sua tramitação e aprovação. A perspectiva de um ciclo de políticas proposta por Bowe, Ball e Gold (1992 apud MAINARDES, 2006) é constituída por diferentes contextos e, dentre eles, o contexto de influência e o contexto da produção de texto. Esses contextos estão interrelacionados, não têm uma dimensão temporal ou sequencial e não são etapas lineares, apresentando arenas, lugares e grupos de interesse envolvendo disputas e embates. Conforme Mainardes (2006, p. 50)

o contexto de influência [é] onde normalmente as políticas públicas são iniciadas e os discursos políticos são construídos. É nesse contexto que grupos de interesse disputam para influenciar a definição das finalidades sociais da educação e do que significa ser educado. Atuam nesse contexto as redes sociais dentro e em torno de partidos políticos, do governo e do processo legislativo. É também nesse contexto que os conceitos adquirem legitimidade e formam um discurso de base para a política.

Os textos políticos são o resultado de disputas e acordos, pois os grupos que atuam dentro dos diferentes lugares da produção de textos competem para controlar as representações da política. Os textos políticos, portanto, representam a política e se configuram no segundo contexto desse ciclo - o contexto da produção do texto. Nessa perspectiva, procuramos, no presente artigo, apresentar por meio do contexto de tramitação e aprovação do PNE (BRASIL, 2014) como os sentidos de mérito previstos no plano foram reconfigurados na legislação específica de três municípios do estado do Rio de Janeiro: Rio de Janeiro, Duque de Caxias e Valença.
Essas cidades foram selecionadas por terem aprovado legislações que regulamentam o processo de seleção dos diretores de escolas públicas nos anos de 2018, 2017 e 2015, respectivamente.

\section{GESTÃo DEMOCRÁTICA: A CONSTRUÇÃO DA AGENDA NA ELABORAÇÃO DO PNE 2014-2024}

A proposta do PNE enviada pelo Poder Executivo à Câmara dos Deputados abordava a gestão democrática em dois dispositivos. Constava como uma das diretrizes previstas no artigo $2^{\circ}$ do projeto de lei $\mathrm{n}^{\mathrm{O}} 8.035 / 2010$, além do art. 9 o que determinava aos estados, ao Distrito Federal e aos municípios a atribuição de aprovar leis específicas disciplinando a gestão democrática da educação em seus respectivos âmbitos de atuação. Concedia, para tanto, o prazo de um ano a partir da publicação da lei. No anexo do documento foi inserida a meta 19 que visava garantir, mediante lei específica aprovada no âmbito dos entes federados, a nomeação comissionada de diretores de escola vinculada a critérios técnicos de mérito e desempenho e à participação da comunidade escolar. $\mathrm{O}$ texto era acompanhado por duas estratégias - o menor número entre o conjunto de metas que o PNE abrangia. Uma que estabelecia prioridade no repasse de transferências voluntárias para os entes federados que aprovassem lei específica disciplinando a nomeação de diretores a partir de critérios técnicos de mérito e desempenho e com a participação da comunidade escolar. A segunda estratégia que tratava da realização de prova nacional para subsidiar o provimento dos cargos de diretores escolares. As duas foram mantidas no texto final.

Segundo Gomes (2015), na primeira fase de tramitação do projeto de lei n. ${ }^{\circ} 8.035 / 2010$ na Câmara dos Deputados foram apresentadas 2.906 emendas, um recorde em se tratando de uma proposição legislativa ordinária. Dessas, cerca de 3\% (74 emendas) buscavam incidir sobre a meta 19 e suas estratégias. No Senado, ampliou-se para dois anos o prazo dos entes federados para o cumprimento do disposto no art. 9o, substituindo-se a aprovação de leis específicas pelo encaminhamento de projeto de lei ao poder legislativo local. No retorno à Câmara, segundo a autora "considerou-se que o comando havia perdido muito de sua força impositiva, e o texto final combinou a proposta de leis específicas com o prazo de dois anos para aprovação ou adequação de legislação local sobre o tema" (GOMES, 2015, p. 149). Por fim, finaliza a autora, o texto preservou a ideia de que a gestão democrática deveria ser associada a critérios técnicos de mérito e desempenho e explicitou a proposta de consulta pública à comunidade escolar. Porém, como foi suprimida a referência à direção escolar, não ficou explícito em que aspectos da gestão 
democrática tais critérios e consulta pública devem ser aplicados (GOMES, 2015, p. 149).

Cabe destacar que os critérios de seleção para diretores de escola deveriam estar vinculados a critérios técnicos de mérito e desempenho sem a menção à eleição direta. Segundo Gomes (2015, p. 146),

a análise das notas taquigráficas das audiências realizadas na Câmara dos Deputados durante a tramitação da proposta mostra que se perdeu a oportunidade de aprofundar a discussão sobre essa vertente do plano, sobretudo as lições aprendidas nas experiências implementadas a partir da redemocratização. O tema foi ofuscado pelo debate sobre o financiamento da educação, avaliação e outros que se sobrepuseram na agenda. Não foi realizada nenhuma audiência pública com o tema gestão democrática.

Tendo em vista o debate sobre legislar acerca da gestão democrática e do processo de seleção de diretores de escolas públicas prevaleceu, ao longo da tramitação do PNE, a garantia da autonomia dos entes federados. Nesse aspecto, destacamos duas questões que orientam o presente texto: qual a natureza das legislações específicas aprovadas por municípios do estado do Rio de Janeiro e quais os sentidos definidos para a categoria mérito presentes nessas legislações. No caso dos entes federados, espera-se que a elaboração e aprovação dos planos de educação ocorram por meio de diferentes percursos em contextos diversos, conforme o movimento político de cada estado ou município, que inclui: a realização ou não de audiências públicas, consultas à comunidade, a atuação do corpo técnico do poder executivo e a composição do poder legislativo. Destacamos, entretanto, que nem sempre a legislação local está alinhada à legislação nacional.

Nesse aspecto, Lima (2011) afirma que a produção de uma regra não garante, obrigatoriamente e automaticamente a sua reprodução por parte de quem age e toma decisões. Segundo o autor, por vezes, podem constituir bons indicadores das dificuldades ou incapacidades de resolver problemas e de concretizar mudanças decretadas, procurando compensar o déficit de mudança através de recursos retóricos e discursos doutrinais ou da reelaboração de certas regras (LIMA, 2011, p. 174). Pode, ainda, demonstrar diferentes graus do que o autor denominou infidelidade normativa. No caso da educação pública oferecida pelas escolas portuguesas, a orientação para a ação organizacional é dada pelo Ministério da Educação em um modelo centralizador, diferente do operado no Brasil, em que o Ministério da Educação e diferentes órgãos que o assessoram como o Conselho Nacional de Educação (CNE) e o Instituto Nacional de Estudos e Pesquisas Educacionais Anísio Teixeira (INEP) produzem normas e políticas, mas esbarram na autonomia relativa dos demais entes federados - estados e municípios nos encaminhamentos de seus sistemas educacionais. Essa autonomia relativa se materializa, por exemplo, no processo de seleção de diretores de escola com destaque para os cenários de definição do mérito de cada candidato, objeto de análise deste artigo.

No caso da regulamentação da gestão democrática, a estratégia 19.1 do PNE determina (Lei no 13.005, de 25 de junho de 2014):

priorizar o repasse de transferências voluntárias da União na área da educação para os entes federados que tenham aprovado legislação específica que regulamente a matéria na área de sua abrangência, respeitando-se a legislação nacional, e que considere, conjuntamente, para a nomeação dos diretores e diretoras de escola, critérios técnicos de mérito e desempenho, bem como a participação da comunidade escolar (BRASIL, [2014], grifo nosso).

As diferentes ressignificações do que seja "legislação específica" tem se apresentado de formas muito variadas nas redes municipais do estado do Rio de Janeiro. O município de Duque de Caxias (RJ) regulamentou a gestão democrática, inicialmente, através do Decreto no 6.542 , de 11 de maio de 2015, que dispõe sobre eleições para diretores e vice-diretores das unidades escolares do município. No entanto, em $1^{\circ}$ de novembro de 2017 o mesmo município aprovou a Lei no 2.864, que regulamenta a gestão democrática e o processo de seleção dos diretores das escolas públicas. Dois procedimentos legais distintos em dois contextos políticos distintos tendo em vista que em 2016 houve eleições municipais que mudaram a configuração político-partidária de Duque de Caxias $^{2}$. Já o município de Valença (RJ) regulamentou a gestão democrática através da Resolução no 003/2015, de 5 de novembro de 2015, da Secretaria Municipal de Educação que estabelece normas para eleição de diretor e diretor adjunto das escolas/creches da rede municipal de ensino. A Secretaria Municipal de Educação do Rio de Janeiro, por sua vez, aprovou, em 29 de setembro de 2017, a Resolução no 20 que dispõe sobre o processo de seleção de gestores das unidades escolares da rede pública do sistema municipal de ensino da cidade do Rio de Janeiro. Como afirmado por Carvalho (2012, p. 115), é preciso levar em conta que nenhum modo de escolha para diretores de escola é neutro.

Nosso pressuposto é de que o termo "legislação específica" foi utilizado na estratégia 19.1 do PNE em

\footnotetext{
2 No período 2012-2016 a cidade foi governada por Alexandre Cardoso (PSD) e, em 2016, Washington Reis (PMDB) foi eleito para o período 2017-2021 na coligação "Rumo ao futuro" que reuniu PMDB/PSL/PPS/ PRP/PHS/PSB.
} 
atenção à autonomia dos demais entes federados. A legislação dos estados e municípios para disciplinar a gestão democrática e o processo de seleção dos diretores de escolas públicas precisa estar alinhada ao PNE, à Lei orgânica dos municípios e à Constituição dos estados tendo em vista a competência legislativa de cada matéria. Acreditamos que, em relação à meta 19 e suas estratégias, o legislador, ao produzir o texto da política, oscilou entre dois termos jurídico-normativos: no artigo 9ํㅡㄹ menciona a aprovação de lei específica, mas na estratégia 19.1 determina a aprovação de legislação específica (grifos nossos).

Compreendemos que lei é o conjunto de normas dispondo sobre determinada matéria e legislação é o conjunto de leis que vigoram no ordenamento jurídico, logo, é formada pela reunião dos códigos, das leis especiais, das normas, portarias, resoluções, etc., ou seja, toda a normativa em vigor. Nesse sentido, acreditamos que há uma espécie de escala que mede a democracia conforme a gestão democrática é disciplinada ou regulamentada em um determinado ente federado. Caso a regulamentação do processo de seleção de diretores ocorra por decreto do prefeito,resolução ou portaria do secretário de Educação ou através de lei, a participação da comunidade escolar e local e dos destinatários da política será diferente. A lei é de uso exclusivo do poder legislativo. As portarias, decretos e resoluções emanam do poder executivo. Por conta disso, os contextos de influência que irão permear a produção dos textos legais também serão diferentes de modo que vozes serão mais ou menos silenciadas bem como as possibilidades de revogação da norma serão mais ou menos democráticas e participativas, promovendo uma escala democrática no que diz respeito à participação dos destinatários da política na sua elaboração e aprovação. Dessa maneira, a elasticidade do termo legislação específica abarca uma lei, um decreto, uma resolução ou mesmo uma portaria. Cada uma dessas legislações é aprovada em diferentes contextos, movimentos políticos e escalas de democracia.

Sobre a meta de gestão democrática e suas estratégias presentes nos planos de educação dos municípios que compõem o estado do Rio de Janeiro, Amaral (2016) identificou quais características são atribuídas ao mérito do candidato à direção das escolas públicas. Conforme a autora, a experiência como docente, a formação em gestão e um candidato que não responda a processos disciplinares; criminais ou tenha pendências judiciais são requisitos para assumir a direção de escola pública. Acreditamos que há diferenças, gradações, aproximações e afastamentos acerca dessas categorias. Nessa perspectiva, procuramos avançar na análise da documentação legal que disciplina o processo de seleção dos diretores aprovada nos municípios do estado do Rio de Janeiro após a sanção dos Planos Municipais de Educação.
Em levantamento realizado no período de março a novembro de 2017 localizamos legislações que disciplinam a gestão democrática aprovadas em três municípios do estado do Rio de Janeiro: Duque de Caxias, Valença e Rio de Janeiro e nosso foco recaiu nas percepções de mérito presentes nos textos legais. Nesse contexto precisamos realizar uma reflexão sobre essa categoria, afinal, há consenso sobre mérito e meritocracia no campo educacional? Quais os sentidos de mérito na sociedade brasileira? E, na perspectiva da seleção de um diretor, o que os documentos definem como mérito para se candidatar a ser diretor de uma escola pública?

\section{O MÉRITO EM PERSPECTIVA: QUE IDENTIDADE DE GESTOR ESTÁ SENDO CONSTRUÍDA?}

No caso do processo de seleção de diretores, o mérito está diretamente associado ao diploma de curso superior, à formação em gestão e a um candidato com uma trajetória sem pendências com a justiça de diferentes naturezas. $\mathrm{Na}$ análise das legislações aprovadas nos três municípios do estado do Rio de Janeiro, compreendemos que há algumas aproximações bem como afastamentos sobre o perfil desejado para o candidato à gestão da escola. Esses movimentos estão relacionados a diferentes questões, como o momento político de cada município, sua cultura e trajetória, as possibilidades postas à participação popular. No Quadro 1 apresentamos os resultados da nossa busca nas legislações complementares já aprovadas nos municípios de Duque de Caxias, Rio de Janeiro e Valença.

Em relação ao mérito para os candidatos à direção das escolas públicas dos três municípios investigados há consenso nas três legislações consultadas que todos deverão ser servidores efetivos concursados, deverão ter experiência docente e que não podem ter pendências administrativas ou judiciais, configurandose no que Amaral (2016) denominou candidato "fichalimpa". O fato de serem servidores concursados afasta completamente da rede a perspectiva patrimonialista de que o executivo ou o legislativo possam interferir na gestão escolar indicando qualquer pessoa para assumir a direção de uma escola. Conforme Schwartzman (2003), o patrimonialismo permanece em seus traços socioculturais ao longo da história da administração pública brasileira, apenas assumindo atualmente outras configurações e nuances. Lima (2012), em relação ao à gestão escolar, afirma o histórico do País acerca de uma a administração das escolas públicas marcada pela troca de favores, por intermediação de interesses e barganhas política, uma forma clientelista de operar a nomeação de diretores feita por políticos que ainda pode ser encontrada em algumas redes públicas de ensino do País. 
Quadro 1 - Municípios e méritos/requisitos

\begin{tabular}{|c|c|}
\hline Município & Mérito - requisitos \\
\hline $\begin{array}{l}\text { Duque de Caxias } \\
\text { Lei no } 2.864 \text { aprovada em } 1^{\circ} \text { de novembro de } 2017\end{array}$ & $\begin{array}{l}\text { - mínimo de } 5 \text { anos de exercício na rede pública municipal de ensino de } \\
\text { Duque de Caxias; } \\
\text { - ter no mínimo } 2 \text { anos de efetivo exercício na unidade escolar até a data } \\
\text { da inscrição; } \\
\text { - possuir curso superior completo em Pedagogia ou licenciatura plena } \\
\text { - possuir graduação em outra área com pós-graduação em Gestão Escolar; } \\
\text { - não estar em débito com prestação de contas de recursos financeiros } \\
\text { recebidos m virtude do cargo diretor e ou vice-diretor. }\end{array}$ \\
\hline $\begin{array}{l}\text { Valença* } \\
\text { Resolução da Secretaria 003/2015 de 5/11/2-15- } \\
\text { Estabelece normas para Eleição de Diretor e Diretor } \\
\text { Adjunto das escolas/creches da Rede Municipal de } \\
\text { Ensino de Valença. } \\
\text { Resolução assinada pela Secretária Municipal de } \\
\text { Educação }\end{array}$ & $\begin{array}{l}\text { - formação mínima a nível de (sic) } 3 \text { o grau, voltado para área de } \\
\text { educação; } \\
\text { - lotado no estabelecimento de ensino; } \\
\text { - licenciatura no Curso de Pedagogia ou Curso Superior na área de } \\
\text { Educação, com Conhecimento em Gestão Escolar; } \\
\text { - ser servidor estatutário do Quadro dos Profissionais da Educação } \\
\text { Municipal; } \\
\text { - tenha no mínimo } 3 \text { (três) anos de efetivo exercício no Quadro dos } \\
\text { Profissionais da Educação Municipal; } \\
\text { - não estar respondendo a inquérito administrativo, nem ter tido } \\
\text { participação comprovada em irregularidade administrativa; } \\
\text { - esteja em situação regular junto à Receita Federal do Brasil; } \\
\text { - esteja apto a exercer plenamente toda e qualquer movimentação } \\
\text { financeira e bancária prevista em face da instituição de ensino que } \\
\text { pretende dirigir. } \\
\text { - esteja em dia com as obrigações eleitorais; } \\
\text { - esteja em exercício na escola ou creche para a qual pretende } \\
\text { candidatar-se; } \\
\text { - não esteja nos } 5 \text { (cinco) anos anteriores a data da eleição para o cargo } \\
\text { ou função, sofrendo efeitos de sentença condenatória; } \\
\text { - não tenha sido condenado em processo disciplinar administrativo em } \\
\text { órgão integrante da Administração Pública direta ou indireta, nos } \\
5 \text { (cinco) anos anteriores à data da eleição para o cargo ou função; } \\
\text { - na data da posse deverá ser apresentada declaração de matrícula em } \\
\text { curso de Gestão Escolar, comprometendo-se a concluí-lo no prazo de } \\
\text { (02) dois anos. }\end{array}$ \\
\hline $\begin{array}{l}\text { Rio de Janeiro } \\
\text { Resolução SME no } 20 \text { de 29/9/2017 que Dispõe sobre o } \\
\text { processo de Seleção de Gestores das Unidades Escolares } \\
\text { da Rede Pública do Sistema Municipal de Ensino da } \\
\text { Cidade do Rio de Janeiro. }\end{array}$ & $\begin{array}{l}\text { - Detentores de cargo efetivo de professor e/ou especialista de educação em } \\
\text { atividade e com origem na Secretaria Municipal de Educação do Rio de } \\
\text { Janeiro; } \\
\text { - mínimo de } 5 \text { anos em regência de turma em unidade escolar na rede } \\
\text { pública municipal de ensino do Rio de Janeiro ou a permanência por } \\
3 \text { anos em cargo comissionado ou função gratificada em unidade escolar } \\
\text { nesta rede; } \\
\text { - estejam com a prestação de contas de recursos federais ou municipais } \\
\text { em alcance, ou seja, com mais de duas prestações de contas pendentes de } \\
\text { aprovação; } \\
\text { - não poderão candidatar-se servidores que tenham sido penalizados, após } \\
\text { conclusão de sindicância administrativa e/ou inquérito administrativo, } \\
\text { com penalidade decorrente de ato de improbidade administrativa que } \\
\text { importam enriquecimento ilícito, publicada em Diário Oficial, nos } \\
\text { últimos cinco anos; que tenham sido exonerados do cargo comissionado } \\
\text { de Diretor IV em alguma unidade escolar da Rede Pública municipal de } \\
\text { ensino da cidade do Rio de Janeiro no mandato anterior ao atual processo } \\
\text { de seleção de gestores das unidades escolares. }\end{array}$ \\
\hline
\end{tabular}

*Um requisito interessante no PME de Valença é a exigência para os atuais ocupantes das funções de Diretor e Diretor Adjunto de comprovação de todas as prestações de contas de adiantamentos e repasses recebidos bem como dos rendimentos obtidos através de festividades na própria escola. A promoção de festividades nas escolas é corriqueira, contemplando arrecadação de dinheiro para festas juninas e do dia das crianças, implicando inclusive na venda de alimentos e diversão, movimentando em alguns casos uma considerável quantia de recursos nem sempre publicizadas de forma transparente pela gestão da escola.

Fonte: Elaborado pela autora com base nos documentos oficiais dos municípios. 
Outro critério exigido dos candidatos está relacionado à experiência prévia como docente e ou profissional da educação de, pelo menos, três anos. Essa experiência pode compreender a regência de turma ou demais experiências como profissional da educação - orientadores pedagógicos, coordenadores ou orientados educacionais, dentre outros. Nesse sentido, é importante observar quais servidores são considerados profissionais da educação dentro do quadro de cada município tendo em vista a autonomia dos entes federados.

A exigência da formação em Gestão aparece de formas variadas. Duque de Caxias exige do candidato pós-graduação em gestão escolar, requisito atrelado ao que está definido nos documentos legais (BRASIL, 1996; BRASIL, 2006). O município de Valença exige licenciatura no curso de Pedagogia ou curso superior na área de Educação, com conhecimento em Gestão Escolar, no entanto não fica claro que tipo de conhecimento em Gestão Escolar é esse e qual a carga horária mínima exigida. Adicionalmente, Valença exige do candidato, na data da posse, a apresentação de declaração de matrícula em curso de Gestão Escolar, comprometendo-se a conclui-lo no prazo de dois anos. A resolução aprovada no município do Rio de Janeiro traz outra compreensão desse perfil ao não exigir formação em nível superior ou mesmo em gestão do candidato, apesar da exigência de licenciatura plena para o exercício da gestão escolar (BRASIL, 1996; BRASIL, 2006). Como ainda há docentes na rede carioca com formação em nível médio, modalidade Normal, inferimos que há uma espécie de infidelidade normativa da rede ampliando o escopo de potenciais candidatos e, provavelmente, apostando que essa formação irá se construir em serviço.

Outra questão relacionada ao perfil do candidato e seu ethos reside no fato da necessidade de conhecer a realidade da escola a qual irá se candidatar - no caso de Valença e Duque de Caxias isso fica claro, o que significa que a seleção se realiza na própria escola através de candidatos que conheçam a realidade em que irão atuar. Acreditamos que isso pode garantir maior legitimidade ao candidato porque a comunidade terá um rosto familiar se candidatando à direção a escola. No caso carioca, o universo do processo seletivo está ampliado uma vez que o servidor poderá se candidatar a qualquer escola da rede, mesmo que não conheça a comunidade e a realidade em que ela esteja inserida. Esse mecanismo pode ser visto como mais democrático e inclusivo, mas também pode provocar outros resultados tendo em vista algumas desconfianças da comunidade escolar em "dar" seu voto a um rosto desconhecido.

Avaliamos que as formas como cada ente federado ressignifica e hibridiza a categoria mérito se apresenta através de distintas maneiras tendo em vista a autonomia dos entes federados, o momento político vivido em cada município/estado, as infidelidades normativas e a forma elástica como se apropriam da norma que orienta a ação, no caso, o PNE.

\section{CONSIDERAÇÕES FINAIS}

Conforme Barbosa (2003), a meritocracia pode ser definida, no nível ideológico, "como um conjunto de valores que postula que as posições dos indivíduos na sociedade devem ser consequência do mérito de cada um. Ou seja, do reconhecimento público da qualidade das realizações individuais" (BARBOSA, 2003, p. 22). O discurso oficial sobre a identidade dos diretores em uma perspectiva da gestão democrática, princípio determinado nos diferentes documentos oficiais que orientam a educação brasileira, determina que sua seleção deva se basear no mérito.

A proposta de exigir a aferição do mérito do candidato à direção da escola se afasta das ciladas patrimonialistas porque significa que as pessoas serão comparadas e classificadas tomando-se por base o desempenho relativo de cada uma e que nenhum outro fator - herança, relações pessoais, poder político - pode ser levado em conta no processo classificatório (BARBOSA, 2003, p.33). Nesse contexto, o critério que deve servir de parâmetro para as hierarquias sociais está dado, logo cabe definir os instrumentos para selecionar os melhores candidatos. Essa descrição, como afirma Barbosa (2003), parece óbvia e simples, mas na prática tudo se complica e pode gerar dilemas, infidelidades normativas e diferentes critérios que estão relacionados ao movimento da democracia no País e ao momento que cada rede pública de ensino vivencia.

Silva (2011) afirma que a defesa do mérito e do sistema de cargo para diretor garante uma identidade de conhecimento técnico que vai em direção contrária à compreensão de que qualquer professor competente da escola possa administrá-la. Conforme Arelalo, Jacomini e Carneiro (2016) essa tendência reforça a ideia de que o desempenho da escola está centrado na figura do diretor e o reitera como preposto do Estado, indo na contramão de propostas de gestões colegiadas, em que a responsabilidade pela escola é compartilhada e apoiada no conselho escolar como órgão deliberativo.

A identidade dos diretores, conforme Silva (2011, p.212), é o conjunto das representações colocadas em circulação tanto pelos discursos oficiais quanto pelo discurso dos próprios, que são relativos aos modos de ser e agir do gestor da escola no exercício de suas funções. Nesse sentido, indagamos se exigir mérito do candidato a diretor está em conformidade com uma perspectiva 
de gestão democrática. Afinal, qual é a régua que mede esse mérito? Como destacado por Barbosa (2003, p. 71), "o mérito, resultado do desempenho e das diferenças substantivas individuais, depende do indivíduo e de suas especificidades - nem todos o possuem ou podem alcançá-lo".

$\mathrm{Na}$ perspectiva da análise do mérito no processo seletivo, o perfil do diretor desejado pela rede e pela comunidade será componente fundamental dependendo dos encaminhamentos que cada rede implementar, assim como a identidade do diretor que irá assumir a gestão da escola pública. A resolução do processo seletivo de diretores assinada pelo Secretário de Educação do município do Rio de Janeiro (DIÁRIO OFICIAL DO MUNICÍPIO DO RIO DE JANEIRO, 2017, p. 56) afirma que "a liderança positiva do gestor é preponderante na construção do sucesso escolar". Nesse aspecto, a Secretaria busca selecionar um líder que não precisa ter formação específica, mas que tenha "responsabilidade com o público e o comprometimento com a excelência dos serviços que executa" (2017, p. 56).

Ainda em terreno frágil, a gestão democrática nas escolas públicas oscila entre a seleção na perspectiva de construção de uma identidade para o diretor ora como um líder, ora como um gestor que promova uma atuação colegiada e participativa dando voz a todos e todas que constroem a escola pública brasileira, ou mesmo de um técnico burocrata que garanta as reformas e represente o executivo. A preocupação no processo de seleção por mérito postula que é tão ou mais importante o perfil do diretor do que a forma como ele é selecionado. No caso de Duque de Caxias e Valença, o perfil é bem detalhado, dando indícios de que essas redes tem clareza do profissional que desejam nas escolas. No Rio de Janeiro, a formação foi excluída, mas há a exigência da experiência docente baseado no pressuposto de que essa passagem pela sala de aula contribui significativamente para um bom desempenho do diretor.

Acreditamos que tanto na forma como o diretor é selecionado, assim como o perfil desejado, o diretor deverá ter sempre uma escola justa como meta. $\mathrm{Na}$ perspectiva de Walzer (2003, p. 271 apud VALLE, 2013, p. 667): "a justiça não se relaciona só com os resultados, mas também com a vivência da educação" e essa vivência precisa ocorrer em uma escola e uma gestão democráticas.

\section{REFERÊNCIAS}

AMARAL, Daniela Patti do. Mérito, desempenho e participação nos planos municipais de educação: sentidos da gestão democrática. RPGE - Revista on line de Política e Gestão Educacional, Araraquara v. 20, n. 03, p. 385-404, 2016. https://doi.org/10.22633/rpge.v20.n3.9732
ARELARO, Lisete Regina Gomes; JACOMINI, Márcia Aparecida; CARNEIRO, Silvio Ricardo Gomes. Limitações da participação e gestão democrática a rede estadual paulista. Educação e Sociedade, Campinas, v. 37, n. 137, out.-dez. 2016 https://doi.org/10.1590/es0101-73302016167343

BARBOSA, Livia. Igualdade e Meritocracia: a ética do desempenho nas sociedades modernas. 4. ed. Rio de Janeiro: Editora FGV, 2003.

BRASIL. Conselho Nacional de Educação. Resolução CNE/CP no 1, de 15 de maio de 2006. Institui Diretrizes Curriculares Nacionais para o Curso de Graduação em Pedagogia, licenciatura. Diário Oficial da União, Seção 1, Brasília, DF, p. 11, 16 maio 2006. https://doi.org/10.1590/ s0101-73302006000400014

BRASIL. Projeto de Lei 8.035/2010. Brasília, DF: Câmara Federal, 2010. Disponível em: http://www.camara.gov.br/ proposicoesWeb/prop_mostrarintegra;jsessionid=DE675521 D54289C3950413A0A52F1F08.proposicoesWebExterno2? codteor $=831421 \&$ filename $=\mathrm{PL}+8035 / 2010$. Acesso em: 2 nov. 2017.

BRASIL. Constituição da República Federativa do Brasil. Brasília: Senado, 1988. Disponível em: http://www.planalto. gov.br/ccivil_03/constituicao/constituicaocompilado.htm. Acesso em: $\overline{2} 1$ out. 2017. https://doi.org/10.11606/d.2.2010. tde-13122010-160747

BRASIL. Lei no 13.005, de 25 de junho de 2014. Aprova o Plano Nacional de Educação - PNE e dá outras providências. Diário Oficial da União, Brasília, DF, 25 jun. 2014. Disponível em: https://www.planalto.gov.br/ccivil_03/ ato2011-2014/2014/lei/113005.htm. Acesso em: 23 maio 2019. https://doi.org/10.19177/prppge.v8e132014276-286

BRASIL. INEP - Instituto Nacional de Estudos e Pesquisas Educacionais Anisio Teixeira. Censo escolar da educação básica. Brasília, DF: INEP, 2016. https://doi.org/10.1590/ s2176-6681/371614642

BRASIL. Lei no 9.394, de 20 de dezembro de 1996. Estabelece as Diretrizes e Bases da Educação Nacional. Diário Oficial da União, Brasília, DF, 20 dez. 1996. Disponível em: http://legis.senado.gov.br/legislacao/ ListaTextoIntegral.action?id=75723. Acesso em: 22 out. 2017. https://doi.org/10.11606/d.2.2017.tde-03102017-105747

CÂMARA MUNICIPAL DE DUQUE DE CAXIAS. Projeto de Lei. Dispõe sobre a gestão democrática da educação pública no município de Duque de Caxias e dá outra providencias. Duque de Caxias, RJ: 2017. https://doi. org/10.17648/galoa-cbee-6-29225

CARVALHO, M.J. DE A modalidade de escolha do diretor na escola pública portuguesa. Revista Lusófona de Educação, Lisboa, v. 22, n. 22, p. 103-121, 2012.

PREFEITURA MUNICIPAL DO RIO DE JANEIRO. Secretaria Municipal de Educação. Ato do Secretário. Resolução SME no 20, de 29 de setembro de 2017. Dispõe 
sobre o processo de Seleção de Gestores das Unidades Escolares da Rede Pública do Sistema Municipal de Ensino da Cidade do Rio de Janeiro e dá outras providências. Diário Oficial do Rio de Janeiro, Rio de Janeiro, 28 dez. 2017. https://doi.org/10.17771/pucrio.acad.26443

GOMES, Ana Valeska Amaral. Gestão Democrática no Plano Nacional de Educação. Câmara dos Deputados, 2015. In: GOMES, Ana Valeska Amaral e BRITTO, Tatiana Feitosa. Plano Nacional de Educação: construção e perspectivas. Brasília: Câmara dos Deputados/Edições Câmara/Edições Técnicas, 2015. https://doi.org/10.18366/conae.2015.0001

LIMA, Maria de Fátima Magalhães. Modalidades de escolha e de provimento de diretores escolares: desafios e alternativas para a gestão democrática e o alcance da qualidade da educação. [2012]. Disponível em: http://www. anpae.org.br/iberoamericano2012/Trabalhos/MariaDe FatimaMagalhaesDe Lima_res_int_GT8.pdf. Acesso em: 23 out. 2017. https://doi.org/10.17771/pucrio.acad.38466

LIMA, L. C. Administração Escolar: estudos. Porto, Portugal: Porto Editora, 2011. https://doi.org/10.21814/ rpe.3047

LIMA, L. C. Gestão democrática das escolas: do autogoverno à ascensão de uma pós-democracia gestionária. Educação e Sociedade, Campinas, v. 35, n. 129, p. 1067-1083, out./dez. 2014. https://doi.org/10.1590/es0101-73302014142170

LÜCK, Heloisa. Mapeamento de práticas de seleção e capacitação de diretores escolares. São Paulo: Fundação Vitor Civita, 2011.

MAINARDES, Jefferson. Abordagem do ciclo de políticas: uma contribuição para a análise de políticas educacionais. Educação e Sociedade, Campinas, v. 27, n. 94, p. 47-69, jan./ abr. 2006. https://doi.org/10.1590/s0101-73302006000100003

MENDONÇA, Erasto Fortes. Estado Patrimonial e gestão democrática do ensino público no Brasil. Educação \& Sociedade, Campinas, v. 22, n. 75, p. 84-108, ago. 2001. https://doi.org/10.1590/s0101-73302001000200007

PREFEITURA MUNICIPAL DE VALENÇA. Boletim Oficial, Valença, n. 719, p. 1-6, 5 nov. 2015.

SCHWARTZMAN, Simon. Nota sobre o patrimonialismo e a dimensão pública na formação da América Latina contemporânea. 12/10/2006. Disponível em: http://www. schwartzman.org.br/simon/patrimonialismo06.pdf. Acesso em: 30 jun. 2017.

SILVA, Joyce Mary Adam d Paula. A construção da identidade de diretores: discurso oficial e prática. Educação em Revista, Belo Horizonte, v. 27, n. 3, p. 211-230, dez. 2011. https://doi. org/10.1590/s0102-46982011000300011

SOUZA, Ângelo Ricardo de. Explorando e construindo um conceito de gestão escolar democrática. Educação em Revista, Belo Horizonte, v. 25, n. 3, p.123-140, dez. 2009. https://doi.org/10.1590/s0102-46982009000300007
VALLE, I.R. (In)Justiça escolar: estaria em xeque a concepção clássica de democratização da educação? Educação e

Pesquisa, São Paulo, v. 39, n. 3, p. 659-671, jul./set. 2013. https://doi.org/10.1590/s1517-97022013005000015

Recebido em: 3/11/2017.

Aprovado em: 23/1/2019.

Publicado em: 8/11/2019.

Endereço para correspondência:

Daniela Patti do Amaral

Av. Pasteur, 250 - Urca

22290-902, Rio de Janeiro, RJ, Brasil

Autora:

Daniela Patti do Amaral

Doutora em Educação pela UFRJ. Professora Associada da Faculdade de Educação e do Programa de Pós-Graduação em Educação da Universidade Federal do Rio de Janeiro (UFRJ), Rio de Janeiro, RJ, Brasil.

Orcid: http://orcid.org/0000-0002-9234-1843

E-mail: danielapatti.ufrj@gmail.com 